1. MBBS, M.Phil

Lecturer

Department of Pharmacology

LUMHS, Jamshoro.

2 MBBS, M.Phil

Assistant professor

Department of Pharmacology LUMHS Jamshoro.

3. MBBS, M.Phil

Lecturer

Department of Pharmacology

LUMHS, Jamshoro.

4. MBBS, M.Phil, PhD

Department of Pharmacology

LUMHS, Jamshoro.

5. MBBS, D. Ophth., PhD

Lecturer

Department of Anatomy

LUMHS, Jamshoro.

6. MBBS, M.Phil, PhD

Department of Pharmacology

Hamdard University Karachi.

Correspondence Address:

Dr. Muhammad Yaqoob Shahani

Department of Anatomy

Lumhs, Jamshoro.

doctor_shahani@hotmail.com

Article received on:

05/12/2019

Accepted for publication:

28/03/2019

\section{EFFECT OF VITAMIN D SUPPLEMENTATION ON GLYCOSYLATED HEMOGLOBIN IN PATIENTS OF TYPE 2 DIABETES MELLITUS TAKING ORAL ANTIDIABETIC DRUG: METFORMIN.}

Gunesh Kumar ${ }^{1}$, Jamil Laghari², Sadat Memon ${ }^{3}$, Nasreen Qazi ${ }^{4}$, Muhammad Yaqoob Shahani ${ }^{5}$, Shahnawaz Jamali ${ }^{6}$

ABSTRACT... Objectives: To assess the outcome of vitamin D as adjunctive therapy in reducing the serum level of glycosylated hemoglobin $(\mathrm{HbA1C})$ in type 2 diabetic patients taking anti-diabetic drug metformin. Study Design: An Observational study. Setting: This study was conducted at the Department of Pharmacology, Liaquat University of Medical and Health Sciences Jamshoro in collaboration with Sindh Institute of Endocrinology \& Diabetes (SIED) Liaquat University of Medical and Health Sciences Jamshoro. Period: December 2017 to May 2018. Material and Methods: We carried out this study on 140 patients. Diagnosed patients of type 2 DM With duration more than 5 years, age between 35 to 60 years, HbA1c equal to or more than $6.0 \%$, and diabetic patients which were on metformin and had vitamin D deficiency (level less than $30 \mathrm{ng} / \mathrm{ml}$ ) were included in the study. Results: Total 140 type 2 diabetic patients were taken in study. At baseline, in Group B, mean HbA1c \pm SD was $7.92 \pm 1.54$ while at 3 months intervention, in Group B, mean HbA1c \pm SD was 7.18 \pm 1.53 . No significant difference in $\mathrm{HbA1c}$ between Group $A$ and $B$ at baseline and after three months of intervention ( $P$ value $=0.46$ ). The mean value of vitamin $D$ before supplementation was $16.23 \pm 3.45$ vs $28.96 \pm 5.25$ after 3 months supplementation. There was a significant increase in $25(\mathrm{OH}) \mathrm{D}$ levels after vitamin D supplementation after 3 months. $(P<0.0001)$. Conclusion: Supplementation of vitamin $D$ did not show any effect on blood sugar control in our patients with type $2 \mathrm{DM}$.

Key words: $\quad$ HbA1C, Type 2 Diabetes Mellitus, Vitamin D.

Article Citation: Kumar G, Laghari J, Memon S, Qazi N, Shahani MY, Jamali S. Effect of vitamin D supplementation on glycosylated hemoglobin in patients of type 2 diabetes mellitus taking oral antidiabetic drug metformin. Professional Med J 2019(11):1925-1930. DOI: 10.29309/TPMJ/2019.26.11.3228

\section{INTRODUCTION}

Increased level of glucose, secretion of reduced insulin and insulin conflict are the disease indications of type 2 Diabetic Mellitus. 382 million people were diagnosed with diabetes in 2013. This figure is increasing from 590 million to 2035. The highest T2DM is available in developing countries. ${ }^{1}$ In 2015, About 57 million diabetic patients in India with first position, 38 million diabetic patients in China on 2nd rank and Pakistan in 4th place with 15 million DM. ${ }^{2}$ The prognosis of diabetes was predicated on blood sugar requirements for decades, especially on the fasting blood sugar and the oral glucose tolerance test for 75 grams. Diabetic Mellitus can be diagnosed by showing reduced hemoglobin $\mathrm{A} 1 \mathrm{c}(\mathrm{HbA} 1 \mathrm{c})$ of $48 \mathrm{mmol}$ / mol( equivalent to $6.5 \%$ ), which has also been endorsed by the $\mathrm{WHO}^{3}$ Vitamin $\mathrm{D}$ shows effect on the glucose equilibrium, affecting the secretion and susceptibility to insulin. This can be indirectly reduced by the effect of insulin resistance (IR) on the metabolism of calcium and phosphate and an increase in the activity of the insulin receptor genes. ${ }^{4}$ For bone integrity vitamin $\mathrm{D}$ play very important role, but it also has multiple effects outside of the skeleton, such as the endocrine system. ${ }^{5}$ Vitamin $D$ is invented in 1930 which is a lipid soluble vitamin and labeled as calciferol. In reality, this vitamin is a hormone precursor and the final by product is accumulated in the body. ${ }^{6,7}$ Calciferol has significant effects on bones, but it plays an essential role in the prevention of colon cancer, breast cancer and prostate cancer by restricting cell division. ${ }^{8}$ About $1.25(\mathrm{OH}) 2$ vitamin D3 is important to homeostasis calcium, which has shown that this drug's impact on the function of immunization and applying 1 and 2 types of diabetes (T2DM). ${ }^{8}$ Glycated hemoglobin 
$(\mathrm{HbA} 1 \mathrm{c})$ is a product of glycation and its concentration is corresponding to the volume of glucose in the blood. ${ }^{9} \mathrm{HbA} 1 \mathrm{c}$ provides a means for assessment of average blood glucose for past three months. The HbA1c complex is developed when the glucose in the blood fixes inevitably (glycates) to hemoglobin. HbA1c serves as a predictor for development of diabetes and related complications. ${ }^{10}$ Considering these studies, one can explain that Vitamin $D$ reduces the intensity of insulin and reduces $\mathrm{HbA1c}$ levels to diabetes patients. ${ }^{11}$ However, additional studies have not been realized with vitamin $D$ effectiveness in improving the glucose homeostasis parameter. ${ }^{12}$ Therefore the rational of this study is that as vitamin $D$ is known for their beneficial effects glycosylated hemoglobin (HbA1c), Little or no research has been conducted in our indigenous population and or local institutions to asses the influence of vitamin $\mathrm{D}$ in type 2 diabetes mellitus (DMT2) patients in accordance with pharmacological and non- pharmacological approaches. This is the first study in this institution that has been conducted to evaluate the effects of vitamin D as adjunctive therapy in decreasing the serum level of glycosylated hemoglobin $(\mathrm{HbA} 1 \mathrm{C})$ in type 2 diabetic patient taking antidiabetic drug metformin.

\section{METHODOLOGY}

\section{Study Design}

We accomplished this study this observational study on 140 diabetic patients at the Pharmacology Department, Liaquat University of Medical and Health Sciences Jamshoro in collaboration with Sindh Institute of Endocrinology \& Diabetes (SIED) LUMHS, Jamshoro for the period of six months. Patients who were diagnosed by type 2 DM taking metformin therapy with duration more than 5 years, age ranging from 35 to 60 years and their $\mathrm{HbA} 1 \mathrm{c}$ was equal to or more than $6.0 \%$, had vitamin $D$ deficiency level less than $30 \mathrm{ng} / \mathrm{ml}$ were incorporated in the study. All known type2 diabetic patients were enrolled through an informed consent for participation in our study. A detailed history, especially regarding onset of diabetes mellitus and the treatment under going was recorded. The biochemical measurements were done for each patient at the beginning of the research and three months later of vitamin $D$ supplementation.

- After taking all aseptic measure, $3 \mathrm{ml}$ of blood was drawn by using $5 \mathrm{cc}$ disposable syringe and collected in EDTA tube.

- The samples were labeled by patient's codes \& date, then samples were sent immediately to Diagnostic \& research laboratory Hyderabad.

- $\quad \mathrm{Hb} A 1 \mathrm{C}$ was done from EDTA bottle by using whole blood through Bio-Rad-Variant-II.

All the patients were equally distributed (A \& B) into two groups with 70 patients in each group. Group A (diabetic patients taking metformin $1000 \mathrm{mg}$ ), Group B (Diabetic patients taking metformin 1000mg and vitamin D 800 IU per day, capsule sunvit 400 IU, Novamet pharma, B.D) daily for three months. Patient care, diet, and physical work did not modify in the course of the research. Patient compliance with the prescribed medicine was monitored by continuous contact with the dairy checklist and by telephone. After three months of vitamin D supplementation, the patients were re-examined and the tests were repeated. Ethical approvals were taken from the ethical review committee of University. All enrolled patients had been informed about their participation in the study and all participants gave their written consent.

\section{Data Analysis}

The patient's data was analyzed by SPSS version 22.0 Frequency and percentage was computed for categorical variables like age (in groups), gender, family history of diabetes mellitus and to compare proportions among groups $\mathrm{X}^{2}$ test was used $A$ (without supplementation) and $B$ (with supplementation). Mean + standard deviation (SD) was calculated for numerical parameters such as age(in years), weight(in $\mathrm{kg}$ ), height(in inches), Body Mass Index $\left(\mathrm{kg} / \mathrm{m}^{2}\right)$, diabetes mellitus duration, $\mathrm{HbA} 1 \mathrm{c}(\%)$, serum vitamin D (before and after treatment) and Student t-test was used to compare the means between groups (A \& B). The significant level of a $p$ value was < 0.05 . 


\section{RESULTS}

This research included 140 patients based on inclusion criteria. In Table-l and Figure-1, at baseline, in Group A (without supplementation), mean $\mathrm{HbA} 1 \mathrm{c} \pm \mathrm{SD}$ (range) was 7.87 $\pm 1.64(6.0$ to $12.0 \%$ ) and in Group B (with supplementation), mean $\mathrm{HbA} 1 \mathrm{c} \pm \mathrm{SD}$ (range) was $7.92 \pm 1.54(6.0$ to $11.5 \%)$. The difference was insignificant $(\mathrm{P}$ value $=0.87$ ). While at 3 months intervention, in Group A (without supplementation), mean HbA1c \pm SD (range) was $7.37 \pm 1.64$ (5.5 to $11.5 \%$ ) and in Group B (with supplementation), mean HbA1c

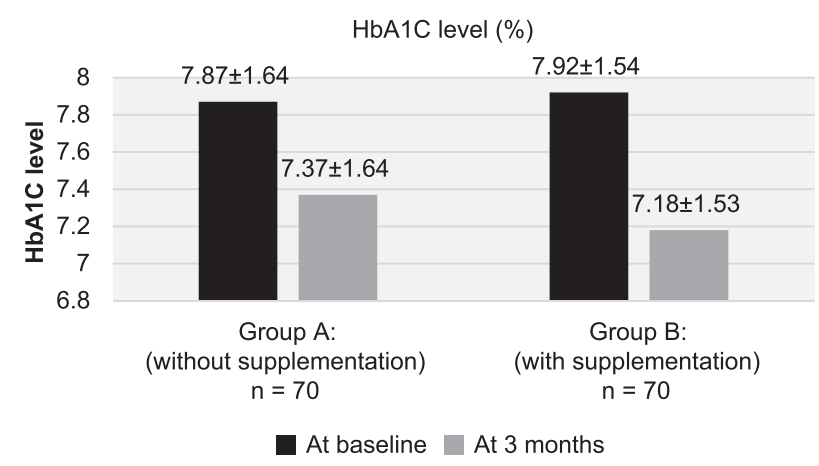

Figure-1. Distribution of subjects according to $\mathrm{HbA1C}$ levels at beginning and after 3 months intervention in both groups $\pm \mathrm{SD}$ (range) was $7.18 \pm 1.53$ (5.0 to $11.0 \%)$. It was observed that Group A and B were similar in accordance with reduction of $\mathrm{HbA} 1 \mathrm{c}$ at baseline and after three months of intervention ( $P$ value $=0.46$ ). As seen in Table-II \& Figure-2, vitamin $D$ concentration were significantly increased by supplementation after 3 months of intervention. The mean value before supplementation (at baseline) was $16.23 \pm 3.45$ (6.3 to $19.4 \mathrm{ng} /$ $\mathrm{mL})$ vs $28.96 \pm 5.25(20.5$ to $40.1 \mathrm{ng} / \mathrm{mL})$ after supplementation (at 3 months intervention) ( $p<$ 0.0001).

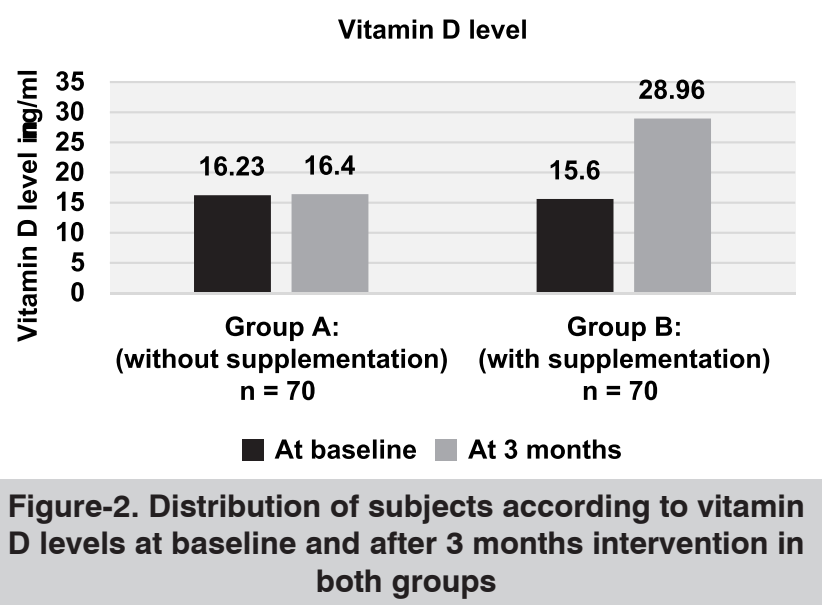

\begin{tabular}{|c|c|c|c|c|}
\hline HbA1c (\%) & $\begin{array}{c}\text { Group A: } \\
\text { (without supplementation) } \\
n=70\end{array}$ & $\begin{array}{c}\text { Group B: } \\
\text { (with supplementation) } \\
n=70\end{array}$ & Difference & P-Value \\
\hline $\begin{array}{l}\text { At baseline } \\
\text { At } 3 \text { months }\end{array}$ & $\begin{array}{l}7.87 \pm 1.64(6.0 \text { to } 12.0) \\
7.37 \pm 1.64 \text { (5.5 to } 11.5)\end{array}$ & $\begin{array}{l}7.92 \pm 1.54(6.0 \text { to } 11.5) \\
7.18 \pm 1.53(5.0 \text { to } 11.0)\end{array}$ & $\begin{array}{l}0.05 \\
0.19\end{array}$ & $\begin{array}{l}0.87 \dagger \\
0.46 \dagger\end{array}$ \\
\hline
\end{tabular}

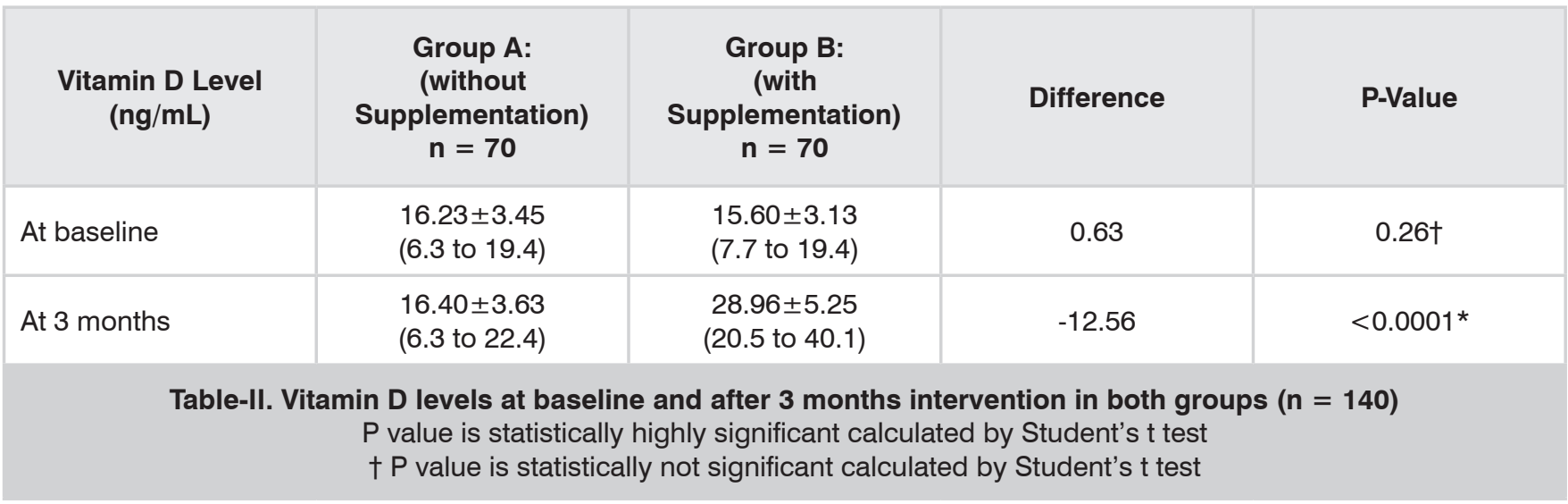




\section{DISCUSSION}

Type 2 diabetes mellitus is a main health concern globally. By the year 2030, the total number of diabetics is estimated to reach 366 million. The lack of Vitamin D is now considered to be a T2DM risk factor.

Diabetes mellitus is the most frequent metabolic disorder in which severe hyperglycemia in particular reactive oxygen species (ROS) increase the development of free radicals, thus vitamin $\mathrm{D}$ which is a potent antioxidant can play an chief role in defending free radical induced tissue destruction, thus it is active in preventing non enzymatic glycosylation of protein. In addition, vitamin D has anti-inflammatory properties, and it can prevent damage to lipids within membranes or lipoproteins by oxygen free radicals attack on lipids, also section of impaired insulin is improved. ${ }^{14,15}$ The objective of this study was to estimate the role of vitamin $\mathrm{D}$ as adjunctive therapy in reducing glycosylated hemoglobin in type 2 diabetic patients taking anti-diabetic drug metformin. We observed the outcome of Vitamin $D$ intervention for three months in our patients with type 2 diabetic mellitus. HbA1c In the present study, at baseline, in Group B (with supplementation), mean $\mathrm{HbA1c} \pm \mathrm{SD}$ (range) was $7.92 \pm 1.54$ (6.0 to $11.5 \%)$. However, at 3 months intervention, mean $\mathrm{HbA} 1$ in Group B (with supplementation) was $7.18 \pm 1.53$ (5.0 to $11.0 \%$ ). It was observed that at baseline and after 12 weeks, HbA1c was not significantly reduced or declined by vitamin $D$ supplementation ( $P$ value $=0.46$ ). In comparison, Krul-Poel et al did not find a significant impact on adding vitamin $\mathrm{D}$ over managing the population of researchers. ${ }^{16}$ This observation is similar to this study.

Many studies have shown relationship between "glycemic control" and "vitamin D levels" but no constant association was observed. ${ }^{17}$ In both types of diabetes, vitamin $D$ is found to be major risk factor reported by many animal as well as human studies. ${ }^{17}$ It was concluded by many studies that vitamin $D$ has key role in proper secretion and function of insulin and also has effect on the "homeostasis" of glucose with the help of activation of vitamin D receptor on Beta cells of pancreas. ${ }^{18}$
In addition, 129 patients with a mean serum calciferol level of 11.2 to $26.1 \mathrm{nmol} / \mathrm{L}$, were randomly selected to either vitamin D3 with 2,000 IU/ day in combination with calcium $200 \mathrm{mg}$ or placebo. After 24 weeks of follow- up, no difference in $\mathrm{HbA1c}$ or metabolic abnormalities was observed in the treatment group, regardless of a significant increase in serum vitamin D concentration. ${ }^{19}$ Most studies evaluated the impact of vitamin D supplement in type 2 diabetes patients did not have a significant impact on glycemic control. ${ }^{20-22}$ The results of this research are in resemble with a studies that the addition of vitamin $D$ is not sufficient evidence of correcting glycemic level in type 2 diabetes mellitus patients. ${ }^{23}$

\section{CONCLUSIONS}

Vitamin D supplements can raise the concentration of vitamin D in the blood, but there is no clinically important effect to decrease the level of $\mathrm{HbA} 1 \mathrm{c}$ in patients with type $2 \mathrm{DM}$.

\section{RECOMMENDATIONS}

Monitoring of vitamin D levels is necessary particularly in people having family history of diabetes. Supplementation of calciferol in type 2 diabetic patients could be useful in the management strategy of the disease. Further research is also needed to assess vitamin $D$ status in type 1 diabetes and other autoimmune diseases. More study is required to conclude whether vitamin $D$ supplements is effective in controlling blood sugar.

\section{ACKNOWLEDGEMENT}

We all authors acknowledge Farooq Ahmed Mangnejo for his statistical analysis using SPSS at advance level and other technical input in the manuscript.

Copyright(C) 28 Mar, 2019.

\section{REFERENCES}

1. Guariguata L, Whiting DR, Hambleton I, Beagley J, Linnenkamp U, Shaw JE. Global estimates of diabetes prevalence for 2013 and projections for 2035. Diabetes Res Clin Pract. 2014 Feb;103(2):137-49.

2. Wild S, Roglic G, Green A, Sicree R, King H. Global prevalence of diabetes: Estimates for the year 2000 and projections for 2030. Diabetes Care. 2004 May;27(5):1047-53. 
3. American Diabetes Association. Diagnosis and classification of diabetes mellitus. Diabetes Care. 2010 Jan 1;33 Suppl 1(SUPPL.1):S62-9.

4. Nada A, Shaheen D. Cholecalciferol improves glycemic control in type 2 diabetic patients: A 6-month prospective interventional study. Ther Clin Risk Manag. 2017 Jul;Volume 13:813-20.

5. Rolim MC, Santos BM, Conceição G, Rocha PN. Relationship between vitamin $D$ status, glycemic control and cardiovascular risk factors in Brazilians with type 2 diabetes mellitus. Diabetol Metab Syndr. 2016 Dec 16;8(1):77.

6. Azar Baradaran, Saeed Behradmanesh HN. Association of body mass index and serum vitamin D level in healthy Iranian adolescents. Endokrynol Pol. 2012;63(1):29-33.

7. Fu J, Prasad HC. Changing epidemiology of metabolic syndrome and type 2 diabetes in Chinese Youth. Curr Diab Rep. 2014 Jan 26;14(1):447.

8. Nasri H, Behradmanesh S, Maghsoudi AR, Ahmadi A, Nasri P, Rafieian-Kopaei M. Efficacy of supplementary vitamin D on improvement of glycemic parameters in patients with type 2 diabetes mellitus; a randomized double blind clinical trial. Journal of renal injury prevention. 2014;3(1):31.

9. Bouchoucha M, Uzzan B, Cohen R. Metformin and digestive disorders. Diabetes Metab. 2011 Apr; 37(2):90-6.

10. Cohen RM, Haggerty S, Herman WH. HbA1c for the diagnosis of diabetes and prediabetes: Is It Time for a Mid-Course Correction? J Clin Endocrinol Metab. 2010 Dec;95(12):5203-6.

11. Randhawa FA, Mustafa S, Khan DM, Hamid S. Effect of Vitamin D supplementation on reduction in levels of $\mathrm{HbA1}$ in patients recently diagnosed with type 2 Diabetes Mellitus having asymptomatic Vitamin D deficiency. Pakistan J Med Sci. 2017 Aug 4;33(4).

12. Kajbaf F, Mentaverri R, Diouf M, Fournier A, Kamel S, Lalau J-D. The association between 25-Hydroxyvitamin D and hemoglobin A1c levels in patients with Type 2 diabetes and stage 1-5 chronic kidney disease. Int J Endocrinol. 2014;2014:1-6.

13. Mohamad MI, El-Sherbeny EE, Bekhet MM. The effect of vitamin D supplementation on glycemic control and lipid profile in patients with type 2 diabetes mellitus. J Am Coll Nutr. 2016 Jul 3; 35(5):399-404.
14. Halliwell B. Vitamin $\mathbf{E}$ and thetreatment and prevention of diabetes: A case for a controlled clinical trial. Singapore Med J. 2002 Sep; 43(9):479-84.

15. Liu S, Lee I-M, Song Y, Van Denburgh M, Cook NR, Manson JE, et al. Vitamin $E$ and risk of type 2 diabetes in the women's health study randomized controlled trial. Diabetes. 2006 Oct 1; 55(10):2856-62.

16. Akshay Kumar S V. Nanda SK, Bharathy N, Ravichandran K, Dinakaran A, Ray L. Evaluation of vitamin D status and its correlation with glycated haemoglobin in type 2 diabetes mellitus. Biomed Res. 2017; 28(1):66-70.

17. Buhary BM, Almohareb O, Aljohani N, Alrajhi S, Elkaissi S, Sherbeeni S, et al. Association of glycosylated hemoglobin levels with vitamin D status. J Clin Med Res. 2017; 9(12):1013-8.

18. Pittas AG, Lau J, Hu FB, Dawson-Hughes B. The role of vitamin $D$ and calcium in type 2 diabetes. A systematic review and meta-analysis. $\mathrm{J}$ Clin Endocrinol Metab. 2007 Jun; 92(6):2017-29.

19. Ryu O-H, Lee S, Yu J, Choi M-G, Yoo HJ, Mantero F. A prospective randomized controlled trial of the effects of vitamin D supplementation on long-term glycemic control in type 2 diabetes mellitus of Korea. Endocr J. 2014; 61(2):167-76.

20. SORIC MM, RENNER ET, SMITH SR. Effect of daily vitamin D supplementation on HbA1c in patients with uncontrolled type 2 diabetes mellitus: A pilot study. J Diabetes. 2012 Mar; 4(1):104-5.

21. Talaei A, Mohamadi M, Adgi Z. The effect of vitamin D on insulin resistance in patients with type 2 diabetes. Diabetol Metab Syndr. 2013; 5(1):8.

22. Jorde R, Sneve M, Figenschau Y, Svartberg J, Waterloo K. Effects of vitamin D supplementation on symptoms of depression in overweight and obese subjects: Randomized double blind trial. J Intern Med. 2008 Dec; 264(6):599-609.

23. George PS, Pearson ER, Witham MD. Effect of vitamin D supplementation on glycaemic control and insulin resistance: A systematic review and meta-analysis. Diabet Med. 2012 Aug; 29(8):e142-50. 


\begin{tabular}{|c|c|c|c|}
\hline \multicolumn{4}{|c|}{ AUTHORSHIP AND CONTRIBUTION DECLARATION } \\
\hline Sr. \# & Author(s) Full Name & Contribution to the paper & Author(s) Signature \\
\hline 1 & Gunesh Kumar & Data interpretation. & \\
\hline 2 & Jamil Laghari & Data collection. & \\
\hline 3 & Sadat Memon & Sample collection. & \\
\hline 4 & Nasreen Qazi & Study design \& Sample & \\
\hline 5 & M. Yaqoob Shahani & $\begin{array}{l}\text { Collection. } \\
\text { Corresponding Author \& } \\
\text { Writing Corrections. }\end{array}$ & \\
\hline 6 & Shahnawaz Jamali & $\begin{array}{l}\text { Statistical analysis and data } \\
\text { interpretation. }\end{array}$ & \\
\hline
\end{tabular}

